International Journal of Instruction

e-ISSN: 1308-1470 • www.e-iji.net

Article submission code:

2019122301471

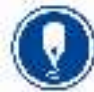

Received: 23/12/2019 Revision: 01/10/2020
April 2021 • Vol.14, No.2

p-ISSN: 1694-609X

pp. $517-534$

Accepted: 23/10/2020

OnlineFirst: 07/02/2021

\title{
Development of an Instructional Design Model for Physical Chemistry based on Multiple Representatives
}

\section{Wilda Syahri}

Department of Chemistry Education, Faculty of Education, University of Jambi, Jambi, 36361 Indonesia, wildasyahri@yahoo.com

\section{Muhaimin}

Department of Chemistry Education, Faculty of Education, University of Jambi, Jambi, 36361 Indonesia, muhaimin_73@yahoo.de

\section{Syamsurizal}

Department of Chemistry Education, Faculty of Education, University of Jambi, Jambi, 36361 Indonesia, syamsurizal68@gmail.com

\section{Muhammad Rusdi}

Department of Chemistry Education, Faculty of Education, University of Jambi, Jambi, 36361 Indonesia, rusdichem@yahoo.com

The purpose of this study was to develop an instructional design model for physical chemistry courses based on multiple representatives for chemistry education students in Indonesia. In this research, several types of development methods were adopted and conducted during the early stages of development. The Lee's approach was used as a methodological framework for the instructional design model of the current study. Prototype I of the instructional design model was validated by some instructional design experts. The validation result of prototype I showed that it had a robust quality with a mean score of 4.45 . This shows that prototype I could be applied to physical chemistry courses in the classroom after some suggested revisions from the instructional design experts were done. After the revision, prototype II was created which improved the content and design of the prototype I in accordance with the recent curriculum, the rules, and elements of education.

Keywords: instructional design model, multiple representatives, physical chemistry courses, chemistry education, chemistry courses

\section{INTRODUCTION}

Physical chemistry is one of the mandatory courses for Chemistry Education Students (CESs) at all Indonesian education university. It has been regarded as a difficult subject based on the opinions of physical chemistry lecturers, researchers, and educators. Many

Citation: Syahri, W., Muhaimin., Syamsurizal., \& Rusdi, M. (2021). Development of an Instructional Design Model for Physical Chemistry based on Multiple Representatives. International Journal of Instruction, 14(2), 517-534. https://doi.org/10.29333/iji.2021.14229a 
CESs face difficulties from the abstract nature of most physical chemistry concepts as well as the difficulty of the language of chemistry. Firstly, chemistry curricula commonly include many abstract concepts and frequently counter-intuitive concepts which are central to further learning (Chandrasegaran et al, 2007; Chittleborough \& Treagust, 2007; Fuad et al, 2017; Janssen et al, 2014). Secondly, lecturers and educators have identified that most CESs face which is the link between the macroscopic, microscopic and symbolic levels in physical chemistry. Unfortunately, only one of the three levels of multiple representatives could be readily observed. Numerous studies support the idea that the interplay between macroscopic and microscopic phenomena is a source of difficulty for many CESs. The interactions and distinctions between the two phenomena are important characteristics of physical chemistry learning in comprehending the concepts (Abubakar et al, 2015; Domagk et al, 2010; İşman, 2011).

These interplay is interconnected and contributed to CESs to understand abstract material of physical chemistry. Tasker and Dalton (2006) who emphasized that chemistry involves processes of change that can be observed not only in terms of changes in color, odor, and bubbles, specifically in the macroscopic or laboratory dimension, but also in terms of changes that can not be observed with the eyes, such as structural changes or processes at the sub-micro level or imaginary molecules. The changes at the molecular level are then depicted in the symbolic level in two ways; qualitatively by using special notation, language, diagrams, and symbolic, and quantitatively by using mathematics (equations and graphs).

The physical chemistry has commonly represented two levels of phenomena, macroscopic and symbolic. The microscopic level (third level) is not discussed in many academic studies (Davidowitz \& Chittleborough, 2009). The role of the third level in learning received less attention, hence CESs had difficulty in transferring knowledge through interconnection between one level to other levels. As the result, it is difficult to obtain the conceptual knowledge needed in the solving problems. Conceptual knowledge is one of the essential parts that CESs should possess when studying chemistry; it should be stored in long-term memory. For its purpose, CESs should be encouraged to use their mental models in connecting those three levels of chemical phenomenon (In'am et al, 2017; Rodriguez et al, 2017; Treagust, 2008; Tana, 2010; Yager, 1994).

Some of the results of previous studies indicated that CESs always experienced difficulties in giving explanations about sub-micro representations based on macroscopic and symbolic representations. CESs tend to use more transformation of macroscopic levels to symbolic, while they are not able to transform from macroscopic and symbolic levels to sub-microscopic levels (Treagust, 2003, 2008). Due to the knowledge gained into memory, it is difficult to access and enter the explanation into long-term memory. The difficulties in transforming those three levels of chemical phenomena are due to CESs' lack of training in learning with sub-micro level representations. Basic chemistry courses tend to separate those three levels. In this case, Treagust (2008) found that CESs who were not trained with external representations would have some difficulties in interpreting the sub-micro structure of a molecule. 
Therefore, chemical learning should be carried out by involving three levels of chemical phenomena to develop new learning models (Isman, 2011; Rastegarpour, 2012; Reiber, 1994; Sunyono, 2018; Treagust, 2008; Tana, 2010; Yakmaci, 2013; Yager, 1994; Yuanita, 2015).

The use and selection of the right learning in presenting material can help CESs to understand everything presented by the teacher. Therefore, it is deemed necessary to develop instructional design to help CESs study and understand physical chemistry independently. Instructional design is defined as an arrangement of procedures used to promote learning. instructional design models are visual representations of the process and used to guide design in many settings and purposes (Lee \& Jang, 2014). They are typically the result of combining abstract principles from general systems theory and analyses of practitioners' experience. To create an effective learning activity, a good planning or design is needed.

\section{METHOD}

\section{Model Design and Concept Development}

This study aimed to construct and validate a multiple representation-based physical chemistry instructional design model through three stages to help and improve CSEs' understanding for physical chemistry. The first stage is the stage of testing theoretical foundations of instructional design to guide model development. The second stage is determining the components of instructional design model and the construction of initial model. The third stage is the internal validation stage by instructional design experts and practitioners through the Delphi-three phase study. The results of this study had been revised and validated by instructional design experts and practitioners. The research was conducted for six months in 2019.

After the initial model, the instructional design model to build CSEs' understanding was constructed, followed by the stages of internal revision and validation by instructional design experts and the views of the instructional design practitioners. Internal revisions and validations by instructional design experts were carried out through the Delphi three-phase study, while views by instructional design practitioners were conducted by asking two questions about their views on the instructional design model (Tracey, 2007, 2009; Sunyono, 2018; Treagust, 2008; Tana, 2010; Yakmaci, 2013; Yager, 1994; Yuanita, 2015).

In the development of the design, some analysis schemes are considered; how to analyze, synthesize, and change the data collection to create an instructional design model. Data collection from this process were arranged in various ways. When arranging data according to a particular format, the design patterns did not suddenly appear likely to emerge, so the analysis scheme seemed to be a dimension that might seek assistance for the development of model by facilitating the examination of data and providing information for the next stage of model development. The important thing to note in the development of instructional design model is the definition of data sources, data collection, data analysis, idea modelling, and representative modelling. 


\section{Sample}

Using convenience sampling method, CSEs involved in the implementation of this study were the 4th Semester of the Chemistry Education of one Indonesian university. Fourth CSEs, 28 females and 12 males were involved. This study was conducted on fourth semester CESs due to very lack of their bility from year to year. CESs do not exactly understand the concepts of physical chemistry. Their imagination in of physical chemistry concepts is still not appropriate. For this reason, researchers develop a new instructional design used to help them understand the concepts of physical chemistry better.

\section{Chemistry education in this study}

Chemistry Education study program has experience in carrying out Training on Development of instructional Design and preparing ICT-based Interactive Learning Media. Moreover, it has several lecturers who are experts in the field of instructional Design and ICT-Based Interactive Learning Media (Chiu, \& Wu, 2009). Relating to academic athmosphere, the interaction between lecturers and students is in very good level. There are very complete facilities and infrastructure for learning in this program. Meanwhile, CESs' independence in learning is not good because there are still many of them studying and relying based on notebooks given by lecturers. Their ability to think quickly is still lack. It can be inferred that it is necessary to develop a new learning design for Physical Chemistry.

\section{Physical chemistry experts}

In this study, physical chemistry experts have professional qualifications in the field of physical chemistry in accordance with their educational background achieved in bachelor, master, and doctoral degrees. Besides, they have carried out a lot of research and service on the physical chemistry and chemistry education. They are trainers and coaches of teachers and lecturers in the physical chemistry at the national level. On the other hand, they have experiences help doctoral students.

\section{Instructional design experts}

Instructional design validation is carried out by instructional design experts with several criteria; being a Ph.D in the field of learning/ education technology, understanding the design of instructional in educational institutions, working as a lecturer of instructional design. In this study, the experts have professional qualifications in the field of instructional design in accordance with their educational background. Besides, they have conducted many studies on the instructional design.

\section{Practitioners}

The view of instructional design practitioners was carried out by instructional design practitioners who meet several criteria. Decision of instructional design practitioner choice is based on the education background, expertise and their profession. 


\section{Research instruments}

Questionnaires were used in this study. Questionnaire is a technique of collecting data through forms that contain questions submitted in writing to someone or a group of people to get answers or responses and information needed.

\section{Data Processing and Interpretation Techniques}

In this development research, it is necessary to process questionnaire data to get maximum results in assessing objects. Each of technique is explained as follows. First, the questionnaire analysis of student characteristics, the data obtained was used to determine how the characteristics of students, and media developed was tailored to the characteristics of students. Second, questionnaire analysis of student needs, data obtained from data collection activities were analyzed and used to determine the level of need for media development. Third, questionnaire for the analysis of physical chemistry material or curriculum, data were analyzed by physical chemistry material that needs multiple representation. Fourth, questionnaire for media expert validation, data were analyzed to find out whether the developed media was good and pedagogical elements were included or not. Fifth, questionnaire for material expert validation of science material in the developed media and material experts, data were analyzed to determine the truth of the explanations of the material displayed in the media. Sixth, questionnaire for product suitability, data were analyzed to find out whether the media developed is in accordance with the concept of the product being developed. Furthermore, instructional design model is developed to promote understanding of instructional (Figure 1).

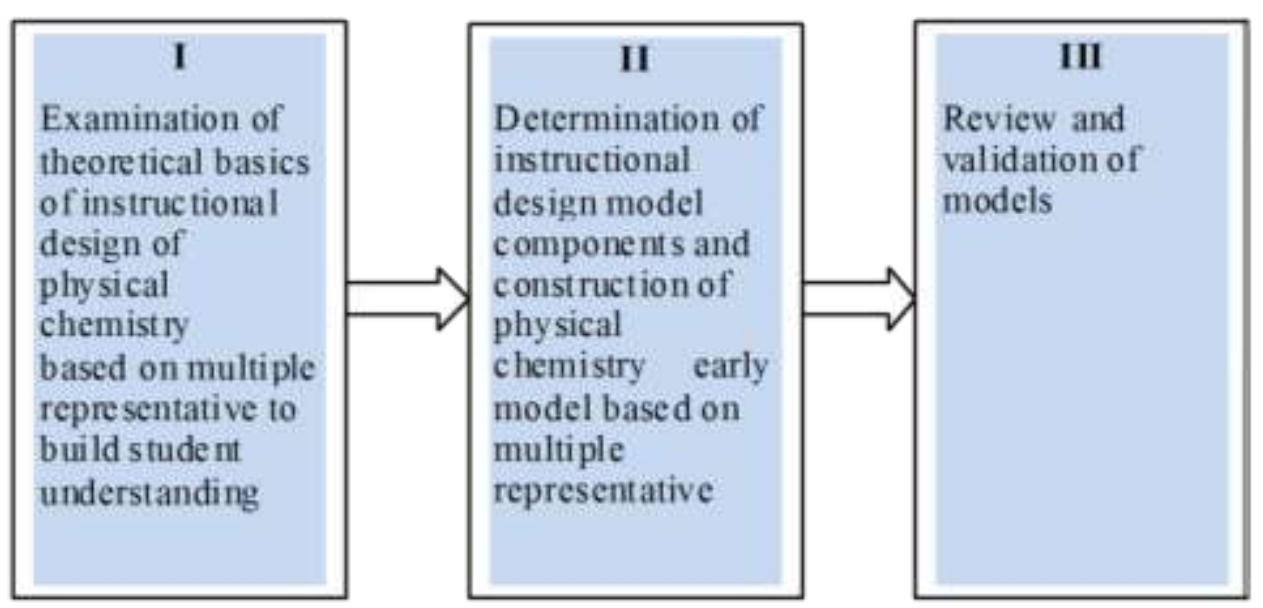

Figure 1

General stages of development of instructional design model

\section{Development Procedure}

There were three hases of development procedure; 


\section{Phase I}

The development phase of physical chemistry course instructional design model began with testing the theoretical basics of physical chemistry instructional design and learning approaches based on multiple representatives to assist and enhance students' understanding.

\section{Phase II}

The initial construction of the physical chemistry course instructional design model based on multiple representatives was conducted by determining the components of instructional design through creating matrix components of pre-existing instructional design models from ASSURE, ADDIE, Smith and Ragan, Dick and Carey, Morrison and Kemp, and the Hanafin and Peck models. These were based on four general steps of instructional design consist of analysis, design, development, and evaluation (Chandrasegaran et al, 2007; Chittleborough \& Treagust, 2007).

\section{Phase III}

Phase III is the review and validation stage of model by instructional design experts and instructional design practitioners.

\section{Development of an instructional design model for Physical Chemistry based on Multiple Representatives}

The main points to consider in this development are the definitions of data sources, data collection, data analysis, idea modeling, and representative modeling (seen in Table 1). The development of this instructional design concept in detail is as follows. Type 1, F101-S1-A1, constructs the concept of a learning design model with a theory-driven approach through literature review and is associated with relevant variables and activities (Lee \& Jang, 2014; Liu et al, 2002). Type 1 follows the following steps.

Table 1

The development of instructional design model concept of physical chemistry based on multiple representatives (Type 1: F1-01-S1-A1)

\begin{tabular}{ll}
\hline Stage & Synthesis Procedure \\
\hline Defining the data source & Determining the basic theory of the conceptual model required \\
\hline Collecting data & Reviewing the relevant literature on available basic theories \\
\hline Analyzing data & $\begin{array}{l}\text { Identifying and rearrange the concepts of variables and activities from } \\
\text { the literature review to produce model components }\end{array}$ \\
\hline Idea modelling & $\begin{array}{l}\text { Creating a logical network based on the relationship between } \\
\text { variables and activities }\end{array}$ \\
\hline Representative modeling & Creating a visual illustration of the relationships in conceptual models \\
\hline
\end{tabular}

The developed instructional design model was a new type. In this study, Research and development method was adopted which includes several steps (Lee \& Jang, 2014; Liu et al, 2002; Mayer, 2003; Perez et al, 1995). Prototype I of the developed instructional design model was then validated by instructional design experts through a questionnaire. 
After validation, the instructional design experts determined that Prototype I could be applied to CESs in the classroom after some revisions. This result in prototype II improves upon the previous instructional design model's content in accordance with the recent curriculum as well as the rules and elements of education.

\section{Design Validation}

After the initial instructional design model has been constructed, revision and an internal validation stage were conducted by instructional design experts. The finalized instructional design model was presented to instructional design practitioners to gather feedback. Design revision and internal validation by the instructional design experts were conducted through a three-phase Delphi study (Lee \& Jang, 2014; Silber, 2007; Tana et al, 2010; Tracey \& Richey, 2007; Tracey, 2009). The feedback from the instructional design practitioners was collected through two questions about their opinions of the instructional design model which had been validated by the instructional design experts.

\section{FINDINGS AND DISCUSSIONS}

\section{Instructional Design and Concept Development}

This study concerned the construction and validation of an instructional design model for physical chemistry based on multiple representatives to assist and enhance CESs learning in the classroom. This study is served as a guide on how to construct and validate an instructional design model. This study was conducted through three main stages. The first stage consists of testing the theoretical component of instructional design to guide the development of a model. The second stage consists of determining the components of an instructional design model and constructing the initial instructional design model. The third stage involves an internal validation by instructional design experts as well as instructional design practitioners through a threephase Delphi study (Lee \& Jang, 2014; Tracey, 2009; Treagust \& Chittleborough, 2003).

The analysis of a selected group of instructional design model development studies revealed four critical dimensions and ten synthesized procedures which form a methodological framework for instructional design model development. After reflecting on the results, several topics of discussion emerged on the dimensions and uses of the methodological framework. The critical dimensions of this methodological framework may be used by instructional design model researchers as a starting point for model development. The first dimension function is closely related to the pertinent features of model development. The last three dimensions of origin, source, and analysis scheme concern the data collection and analysis involved in developing the model. The dimensions and subtypes are also related to target users, focus of model, developmental approach, and other contextual problems in research situations. Once the set of information has been sufficiently defined, a proper method for modeling can be selected and applied. The finer details of the specific techniques, model researchers can use within each of the identified steps. They may be flexible in the specific methods they employ within each step. For instance, to identify heuristic design patterns, a model 
researchers may use techniques such as interviewing designers, observing their tasks, or having them think out loud. It can be utilized on their competence, preferences, or accessibility to certain data (Lee \& Jang, 2014; Silber, 2007; Tana et al, 2010; Tracey \& Richey, 2007; Tracey, 2009).

\section{Interaction Between Theory and Practice in Instructional Design Model Development}

Interactions between theories and practices are extremely desirable because purely theoretical models can lack usability in practice while purely practical models, especially those based on a relatively small sample, can lack of content validity. This tendency towards the interaction between theory and practice is reflected in designbased theory development. Such an approach improves theories by integrating data from real-life settings with results from relevant literature and encourages close interactions between practitioners and researchers. This approach also provides researchers with flexibility when considering multiple contextual variables and iteratively refining designs and theories (Lee \& Jang, 2014; Tana et al, 2010; Tracey \& Richey, 2007; Tracey, 2009; Treagust \& Chittleborough, 2003).

A close interaction exists between model characteristics and model usage. Instructional models are classified into three categories: classroom, product, and system models. These categories are related to the conditions under which a model can be used. The taxonomy and selected features of each category imply that the model's use can influence model characteristics and vice versa. Similarly, these methods can influence the features of a model and type of model desired can suggest a certain method. Instructional design is defined as an arrangement of resources and procedures used to promote learning. instructional design models are visual representations of instructional design process and used to guide design in many settings and for many purposes. They are typically results of the combination of abstract principles of General Systems Theory and analyses of practitioner experience (Tracey, 2009; Treagust \& Chittleborough, 2003). instructional design models can also address learner assessment and problem analysis by identifying and formulating objectives, including the step of developing assessments based on those objectives.

\section{Three-Phase Delphi Study}

A three-phase Delphi study was used to validate the developed instructional design model. The study is an iterative process and in this study, the researcher estimates that the validation of this learning design model could be completed in three stages (İşman, 2011; Lee and Jang, 2014; Tracey and Richey, 2007; Tracey, 2009).

In phase I of the Delphi study, an academic script was given to the instructional design experts for revision and validation. The academic paper contains: 1) A brief background of research; 2) Selection of instructional design components with the reason for selecting those components; 3) Early models of physical chemistry instructional design based on multiple representatives; 4) instructional design functions; 5) Questionnaire. The questionnaire consists of several open questions. The questions were categorized 
into the following topics: instructional design model components, the sequence of components, ease of use, strategy, and parts to be revised.

In phase II of the Delphi study, an academic paper with the following topics: 1) Recommended improvements from the instructional design experts; 2) Questionnaire. This questionnaire contains several follow-up open questions based on phase I's review. The instructional design experts were then given one week to answer these questions.

In phase III of the Delphi study, an academic manuscript containing: 1) Appropriate improvements suggested by the instructional design expert; 2) Questionnaire. The questionnaire consists of one final question based on the review of the Delphi study.

In the development of instructional design models, the scheme of analysis needs to be considered on how to analyze, synthesize, and change the data collected to create instructional design models. Data collected from this process can be organized in various ways. When organizing data in a specific format, previously unseen design patterns may appear, so the analytic scheme is a dimension to assist model development by facilitating the examination of data and providing information for the next stage of model development. Other important factors to be considered in the development of an instructional design model are the definitions of data sources, data collection, data analysis, model ideas, and representative models (Treagust \& Chittleborough, 2003).

The new physical chemistry course instructional design model based on multiple representatives is developed according to the following systematic planning steps. The first step was to conduct the needs analysis. In this analysis, a goal or target analysis was performed to support the desired objectives in this study and to identify the theories related to the desired objectives. Further reference was then made to what is available and how many studies were relevant to the result of the objective analysis.

The second step was to review the references obtained during the first step. All references related to instructional design models were collected and selected as needed. The review results were then combined to define new statements about the instructional design models. The selected reference discusses the theories, instructional design model construction, and instruction in learning with a focus on physical chemistry based on multiple representatives. The third step was to review the content of relevant research, instructional design theories, and physical chemistry based on multiple representatives. The components of instructional design and instructional design model were reviewed under relevant studies. The models, components, and sequences of instructional design theories were then examined. Finally, the theoretical components of physical chemistry based on multiple representatives were then reviewed. The fourth step was to determine the components by collecting all existing components, followed by a selection process to choose the components which support the components of instructional design and physical chemistry based on multiple representatives. The essential components for formulating instructional design were then combined. The fifth step involved sorting and reviewing all the necessary components to further clarify the relationship between each component. Once the relationships have been clearly established, these components were then systematically arranged. The sixth step was to describe whether the 
component in the form of a scheme or as a main component of information and support. A detailed and systematic information on new instructional design formulation was also described in this phase. The seventh step was to conduct an internal validation by instructional design experts on the new instructional design formulation for physical chemistry based on multiple representatives. The eighth step was to describe the use of the new instructional design model to students. The ninth step was to determine the appropriate learning media for physical chemistry based on multiple representatives from the newly-developed instructional design model. The tenth step was to determine the proper teaching method for physical chemistry learning based on multiple representatives from the newly developed instructional design model.

Finally, the development of the new physical chemistry course based on multiple representatives instructional design model began with concept development, where the developed concept was then used as a guide in the development of its products. These products were later tested in the learning process. Prototype I of the instructional design model was then validated by the instructional design experts. The validation results of prototype I was in the form of assessment data and the experts' suggestion. These validation results were then used as a framework of reference for revising prototype I. The types of errors discovered and suggestions from the experts can be seen in Table 2 .

Table 2

Types of mistakes and suggestions from instructional design experts

\begin{tabular}{lll}
\hline Mistake part & Type of mistake & Suggestions for improvement \\
\hline $\begin{array}{l}\text { Instructional design } \\
\text { concept }\end{array}$ & $\begin{array}{l}\text { Instructional design concept } \\
\text { was incomplete }\end{array}$ & $\begin{array}{l}\text { Instructional design concept has to be } \\
\text { equipped in accordance with content and } \\
\text { basic competence }\end{array}$ \\
\hline $\begin{array}{l}\text { References on } \\
\text { instructional design }\end{array}$ & $\begin{array}{l}\text { References on instructional } \\
\text { design were incomplete }\end{array}$ & $\begin{array}{l}\text { References have to be equipped in the e- } \\
\text { book }\end{array}$ \\
\hline
\end{tabular}

A revision process was then conducted based on the instructional design experts' suggestion and advice. After revision, prototype II of the physical chemistry course instructional design model can be seen in Figure 2. 


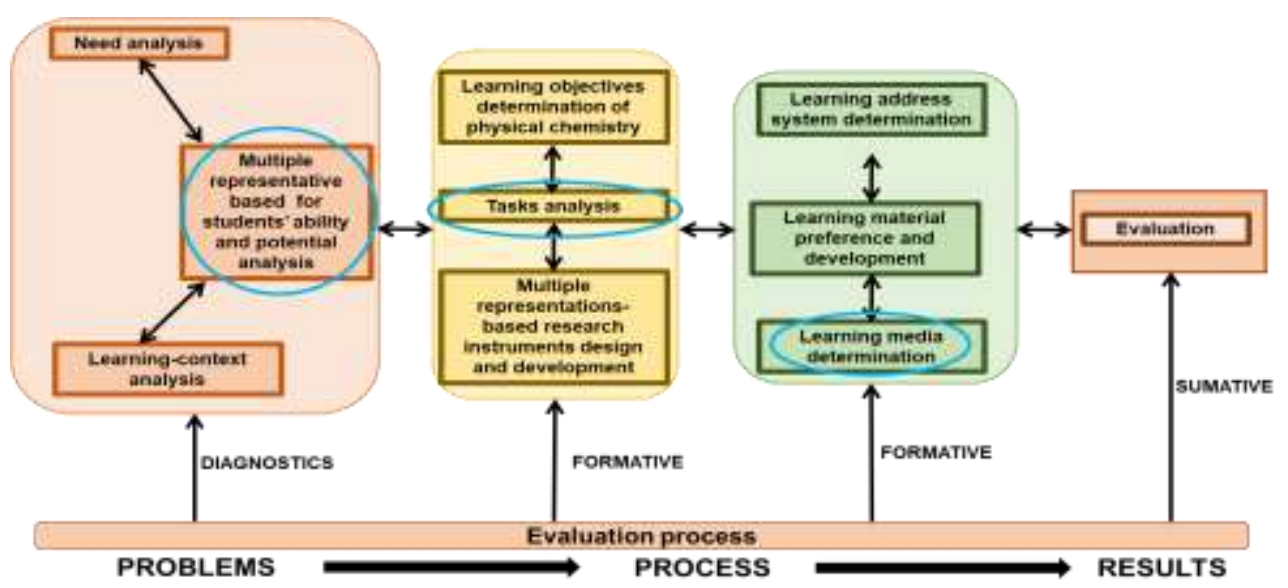

Figure 2

Revised instructional design model of physical chemistry based on multiple representatives

The instructional design model consists of several components which support one another to strengthen the learning process of physical chemistry based on multiple representatives. Each component has a section or important points to support the achievement of the instructional design model of physical chemistry based on multiple representatives. Components of the instructional design model of physical chemistry based on multiple representatives are illustrated in Figure 3.

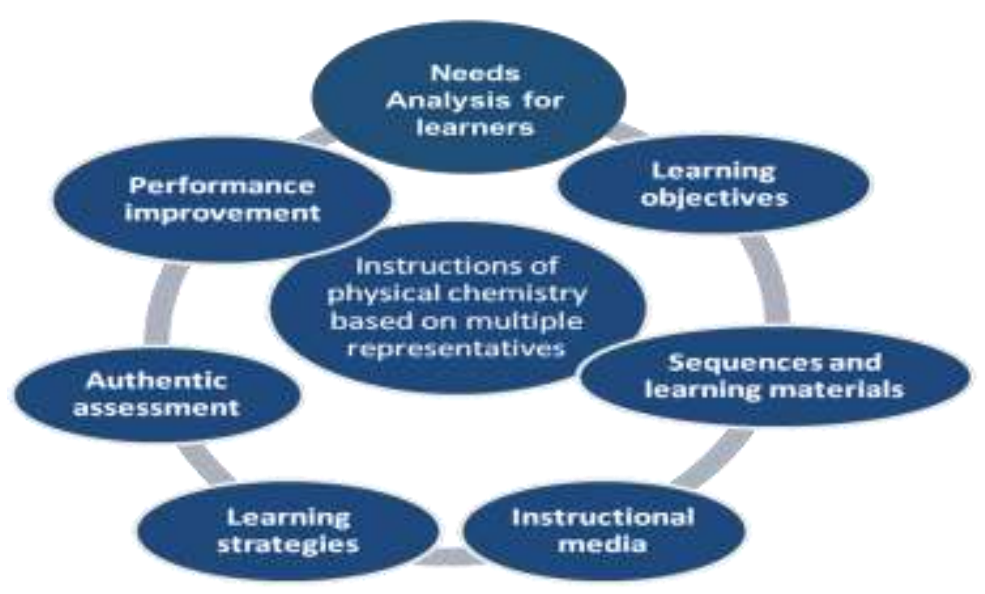

Figure 3

Components of instructional design model of physical chemistry based on multiple representatives 
Prototype II of the instructional design model of physical chemistry based on multiple representatives was then validated by instructional design experts. The quality of prototype II was shown to be very good based on the validation results from the instructional design experts with a mean score of 4.45 (Table 3).

Table 3

Quality of prototype II of the instructional design model of physical chemistry based on multiple representatives (by instructional design experts)

\begin{tabular}{lllll}
\hline \multirow{2}{*}{$\begin{array}{l}\text { Aspects of } \\
\text { assessment }\end{array}$} & Mean score & & & \\
\cline { 2 - 5 } & Expert 1 & Expert 2 & Average & Criteria \\
\hline Aspect of learning & 4.46 & 4.46 & 4.46 & Very good \\
\hline Aspect of content & 4.46 & 4.42 & 4.44 & Very Good \\
\hline Average & 4.46 & 4.44 & 4.45 & Very Good \\
\hline
\end{tabular}

Overall, it can be inferred that this new instructional design model can make physical chemistry courses easier for CESs especially in terms of understanding the abstract concept at a microscopic level. As a result, the time allocation for learning process can be managed more efficiently by applying this instructional design model.

In developing a model of instructional design for Physical Chemistry courses based on multiple representations, it starts with developing concepts. Where the concepts of the development results are used as guidelines in the development of their products. These products are tested in class in the teaching and learning process.

Chart of instructional design models for multiple representation based Physical Chemistry courses consists of several components that support each other to strengthen the learning process of the Physical Chemistry class based on multiple representations. Each component has important parts or things to support the achievement of multiple learning models of Physical Chemistry learning classes based on physical representation. The following are the components of the learning design model of the Physical Chemistry course based on multiple representations.

Chart of instructional design models for Physical Chemistry I courses based on Multiple Representations consists of several components that support each other to strengthen the learning process of Physical Chemistry I courses based on Multiple Representations. Each component has important parts or things to support the achievement of learning design models in the course of Physical Chemistry I based on multiple representations. The typical concept of physical chemistry was delivered in terms of three levels of representation and the development of its instructional design model. It can be followed as an example (Table 4-7).

\section{Component 1. Learners Needs Analysis}

Student's motivation analysis includes persistence, tenacity, energy, imagination, intelligence, emotional state, and interest 


\section{Knowledge of Prerequisites}

The concept of physical chemistry prerequisites includes SI units, pressure, and temperature scale (Cheng \& Gilbert, 2009).

Table 4

Component 2, learning objectives, indicator analysis

\begin{tabular}{lr}
\hline Concept & Indicator \\
\hline Equation of state for ideal gas & - Students will be able to explain ideal gas equation \\
& - Students will be able to explain the laws of ideal gas \\
\hline
\end{tabular}

Table 5

Sequence of indicators

Indicator

Students will be able to ideal gas equation

Students will be able to explain the laws of ideal gas

Table 6

Component 3. sequence and Learning Material

\begin{tabular}{lcllrl}
\hline Concept & Sub Concept & Type of Concept & Level of Representation \\
\hline $\begin{array}{l}\text { Equation } \\
\text { the state for }\end{array}$ & $-\begin{array}{c}\text { The ideal gas } \\
\text { equation }\end{array}$ & $\begin{array}{l}\text { Concepts based } \\
\text { principle }\end{array}$ & on & - Macroscopic \\
ideal gas & $-\begin{array}{c}\text { The laws of } \\
\text { ideal gas }\end{array}$ & & - Symbolic \\
& & & - Submicroscopic \\
\hline
\end{tabular}

Table 7

Component 4, instructional media, media selection

\begin{tabular}{|c|c|c|c|}
\hline Concept & Type of Concept & Level of Representation & Media \\
\hline $\begin{array}{l}\text { - The ideal gas } \\
\text { equation } \\
\text { - The laws of ideal gas }\end{array}$ & $\begin{array}{l}\text { Concepts based } \\
\text { on principle }\end{array}$ & $\begin{array}{l}\text { - Macroscopic } \\
\text { - Symbolic } \\
\text { - Submicroscopic }\end{array}$ & $\begin{array}{l}\text { Pictures, Tables, } \\
\text { Posters, Videos, and } \\
\text { Animations }\end{array}$ \\
\hline
\end{tabular}

\section{Media Usage}

Good use of multiple representations is considered as the key to learning physical chemistry. There is considerable motivation both to learn how CESs use multiple representations when solving problems and to learn how to best teach problem-solving using multiple representations.

\section{Component 5. Learning Strategy}

In terms of authentic contextual strategy, the implementation of learning strategy includes knowledge-based approach, skill-based approach, and cognitive approaches. Meanwhile, in terms of activities for learners, the instructor can then build supporting contextual learning activities which focus on the basic skills and knowledge required to effectively carry out those broad activities. This approach was repeated in several iterations in which enabling learners to get a better appreciation of the overall context and therefore subsequently grasp smaller nuances making up that broader view. 


\section{Component 6. Authentic Assessment}

In component of authentic assessment, learners were required to show their command of what they had learned by applying that knowledge and those skills to real-world tasks. Therefore, essay test assessments can be in forms of Macroscopic, Symbolic, and Submicroscopic.

\section{Component 7. Performance Improvement}

In this component, CESs' mastery improvement in the equation of state for ideal gas concept at multiple representatives (Macroscopic, Symbolic, and Submicroscopic forms).

\section{DISCUSSIONS}

The purpose of this study was to develop an instructional design model for physical chemistry courses based on multiple representatives to be used by CESs. The procedures and findings of the study have implications not only for the use of multiple representatives in ID (Taber, 2009; Treagust, David, \& Chandrasegaran, 2009), but also for the processes involved in validating instructional design models.

\section{Incorporating multiple representatives into instructional design model}

In this study, its focus on the recognition of multiple representation in every step of the instructional design process is the advantage of the multiple representatives design model, thus it has a continuous learner focus. This new multiple representatives instructional design Model, however, has benefits that go beyond the added value given to an instructional intervention. It demonstrates an approach to instructional design model enhancement. This is the 'overlay' approach that involves taking an existing general instructional design model and embedding an additional layer of design procedures that address special concerns (Chiu \& Wu, 2009).

Multiple contextual variables and iteratively refining designs and theories developed by Lee and Jang (2014) Tana et al, (2010), Tracey and Richey (2007), Tracey (2009), Treagust and Chittleborough (2003) are the most common examples of this approach to building instructional design models. This study replicates this approach and provides data supporting its usefulness.

In addition, there are two advantages of this overlay approach of model construction. First, this approach makes feasible to complete the difficult task of developing a new operational instructional design model with the appropriate level of detail by allowing the model developer to focus on several aspects of the new model. Second, the resulting design model typically can be easily mastered by both novices and expert designers because of their familiarity with traditional instructional design models. Thus, the new model is only new in part. It is noted that one need does not make radical changes in existing design habits to expand one's repertoire of design skills. This study resulted in a validated model should be useable by designers regardless of context, content, and learners. Furthermore, this new model should be useable by all instructional designers, novice or expert. These assumptions, however, are yet to be tested. 


\section{Validation in instructional design}

Richey (2005) emphasized that instructional design model validation has been viewed as either internal or external. Internal validation is a confirmation of the components and processes of an instructional design model; external validation, on the other hand, is a validation of the impact of the products of model use. This study demonstrated validation procedures involving expert review, one of the three common internal validation techniques. Expert review is a process whereby instructional design experts critique a given model in terms of its components, overall structure and future use. It is the most expeditious of the internal validation methods. Essentially, this is a cyclical process of model review and critiquing based upon pre-specified criteria, and subsequent model revision based upon the data. Validation procedures of this type can also be viewed as a type of formative evaluation.

Moreover, as in line with Tracey and Richey (2007), the Delphi technique as a framework for multiple representative instructional design used as the validation process in this study involved experts to critique and come to consensus on the components and overall structure of the multiple representatives design model. More specifically, it can be inferred that there were two aspects of this Delphi process that proved invaluable in this study (Gilbert \& Treagust 2009). First, this technique proved successful in part due to the qualifications of the reviewers. The reviewer panel had expertise not only in ID, but also in model construction and use. Selecting these experts was a critical part of the internal model validation process. In addition, the use of electronic communication proved to be an excellent method for receiving feedback. The expert reviewers were given a one-week window to review and reflect on the model in each round, answering several open-ended questions in the first round. This resulted in the most significant model revisions. It provided each reviewer with the opportunity to reflect and comment in a somewhat flexible timeframe. As a consequence, extensive and important data were gathered which led to subsequent model revisions. This study can serve as a model of validation research as well as an application of the theory of multiple representatives.

Further study is a need for more empirical studies that explicate the processes involved in the construction or refinement of instructional design models. Moreover, validation should become a natural part of the model development process. The presence of this research could clarify the processes involved in instructional design model construction and refinement. However, they may also lead to a greater understanding of the instructional design process itself.

\section{CONCLUSIONS}

The instructional design model of physical chemistry based on multiple representatives was developed based on the combination of several instructional design model development. The quality of prototype II of the instructional design model of physical chemistry based on multiple representatives was determined to be very good with an average score of 4.45 . The validation results indicated that prototype II of the instructional design model of physical chemistry based on multiple representatives was feasible to be used in the classroom. Prototype II improved on the content and display of 
prototype I in accordance with the recent curriculum as well as the rules and elements of education.

This study, however, was more than an attempt to apply multiple representative theory. It was an attempt to systematically construct and internally validate an instructional design model. It sought to gather empirical support for the components of this new model rather than relying primarily on personal advocacy as a basis for recommending its use. This study may serve as a framework for others involved in instructional design model construction and validation research.

\section{ACKNOWLEDGEMENTS}

The authors are grateful to the Directorate General of Higher Education from the Ministry of Research, Technology and Higher Education, the Republic of Indonesia for supporting this research.

\section{REFERENCES}

Abubakar, A. B., \& Arshad, M. Y. (2015). Self-directed learning and skills of problembased learning: A case of Nigerian secondary schools chemistry students. International Education Studies, 8 (12), 70.

Chandrasegaran, A. L., Treagust, D.F., \& Mocerino, M. (2007). Enhancing students' use of multiple levels of representation to describe and explain chemical reactions. School Science Review, 88, 325.

Cheng, M., \& Gilbert, J.K. (2009). Towards a better utilization of diagrams in research into the use of representative levels in chemical education. in: J.K. Gilbert \& D. Treagust (Eds.). Multiple Representations in Chemical Education: Models and Modeling in Science Education. Dordrecht: Springer.pp. 55-73.

Chittleborough, G., \& Treagust, D. F. (2007). The modelling ability of non-major chemistry students and their understanding of the sub-microscopic level. Chem. Educ. Res. Pract., 8, 274-292.

Chiu, M.H., \& Wu, H.K. (2009). The roles of multimedia in the teaching and learning of the triplet relationship in chemistry. In: J.K. Gilbert \& D. Treagust (Eds.). Multiple Representations in Chemical Education: Models and Modeling in Science Education. Dordrecht: Springer. pp. 251-283.

Davidowitz, B., \& Chittleborough, G. D. (2009). Linking the macroscopic and submicroscopic levels : Diagram. In: J. Gilbert \& D. Treagust (Eds.). Multiple Representation in Chemical Education: Models and Modeling in Science Education. Dordrecht: Springer. 169-191.

Domagk, S., Schwartz, R.N., \& Plass, J. L. (2010). Interactivity in multimedia learning: An integrated model. Computers in Human Behavior, 26, 1024-1033. 
Fuad, N. M., Zubaidah, S., Mahanal, S., \& Suarsini, E. (2017). Improving junior high schools' critical thinking skills based on test three different models of learning. International Journal of Instruction, 10 (1), 101-116.

Gilbert, J.K., \& Treagust, D.F. (2009). Introduction: Macro, sub-micro and symbolic representations and the relationship between them: Key models in chemical education. In: J. K. Gilbert \& D. Treagust (Eds.). Multiple Representations in Chemical Education: Models and Modeling in Science Education. Dordrecht: Springer.1-8

In'am, A., \& Hajar, S. (2017). Learning geometry through discovery learning using a scientific approach. International Journal of Instruction, 10 (1), 55-70.

İşman, A. (2011). Instructional design in education: New model. The Turkish Online Journal of Educational Technology, 10 (1), 136-142.

Janssen, F. J., Westbroek, H. B., \& van Driel, J. H. (2014). How to make guided discovery learning practical for student teachers. Instructional Science, 42 (1), 67-90.

Lee, J., \& Jang, S. (2014). A methodological framework for instructional design model development: Critical dimensions and synthesized procedures. Education Tech Research Dev, 62, 743-765.

Liu, M., Gibby, S., Quiros, O., Demps, E. (2002). Challenges of being an instructional designer for new media development. Journal of Educational Multimedia and Hypermedia, 11, 195-219.

Mayer, R. E. (2003). The promise of multimedia learning: Using the same instructional design methods across different media. Learning and Instruction, 13, 125-139.

Mammino, L. (2008). Teaching chemistry with and without external representations in professional environments with limited resources. In : J.K Gilbert, Reiner \& Nakhleh (Eds.). Visualization : Theory and Practice in Science Education. Dordrecht: Springer. pp. 155-185.

Perez, R. S., Johnson, J. F., \& Emery, C. D. (1995). Instructional design expertise: A cognitive model of design. Instructional Science, 23, 321-349.

Richey, R. C. (2005). Validating instructional design and development models. In J. M. Spector \& D. A. Wiley (Eds.), Innovations in Instructional Technology: Essays in Honor of M. David Merrill (pp. 171-185). Mahwah, NJ: Lawrence Erlbaum Associates, Publishers.

Rodríguez, C. A., \& Fernández Batanero, J. M. (2017). Aplicación de un aprendizaje basado en problemas en estudiantes universitarios de ingeniería del riego. Journal of Science Education, 18 (2), 90-96.

Silber, K. H. (2007). A principle-based model of instructional design: A new way of thinking about and teaching ID. Educational Technology, 47(5), 5-19. 
Sunyono, S., \& Meristein, A. (2018). The effect of multiple representation-based learning (MRL) to increase students' understanding of chemical bonding concepts. Indonesian Journal of Science Education, 7(4), 399-406

Sunyono, S., \& Sudjarwo, S. (2018). Mental models of atomic structure concepts of 11 th grade chemistry students. In Asia-Pacific Forum on Science Learning and Teaching, 19(1).

Taber, K.S. (2009). Learning at the symbolic level. In: Gilbert, J.K \& D. Treagust (Eds.). Multiple Representation in Chemical Education: Models \& Modeling in Science Education. Dordrecht: Springer. pp. 75-105

Tana, K. C. D., Chandrasegaran, A. L., Treagust, D.F., \& Mocerino, M. (2010). Kinetics of acid reactions: Making sense of associated concepts. Chemistry Education Research and Practice, 11, 267-280.

Tracey, M. W., \& Richey, R. C. (2007). instructional design model construction and validation: A multiple intelligences case. Education Tech Research Dev., 55, 369-390.

Tracey, M. W. (2009). Design and development research: a model validation case. Education Tech Research Dev., 57, 553-571.

Treagust, D. F., \& Chittleborough, G. (2003). The role of submicroscopic and symbolic representations in chemical explanations. Int. J. Sci. Educ., 25(11), 1353-1368 .

Treagust, David F. \& Chandrasegaran, (2009). The efficacy of an alternative instructional programme designed to enhance secondary students' competence in the triplet relationship. In: Gilbert, J.K \& D. Treagust (Eds.). Multiple Representation in Chemical Education: Models \& Modeling in Science Education . Dordrecht: Springer. pp:151-164

Yakmaci-Guzel, B., \& Adadan, E. (2013). Use of multiple representations in developing preservice chemistry teachers' understanding of the structure of matter. International Journal of Environmental and Science Education, 8(1), 109-130.

Yuanita, L., \& Ibrahim, M. (2015). Supporting students in learning with multiple representation to improve student mental models on atomic structure concepts. Science Education International, 2(2). 